\title{
Predictive Factors of Blood Loss and Hospital Stay in Patients With Major Lumbosacral Surgeries: A Multi-Center, Prospective, Cross-Sectional Survey
}

\author{
Mojtaba Miri ${ }^{1}$; Gholamreza Farzanegan ${ }^{1}$; Nasim Khosravi ${ }^{1}$; Majid Rezvani ${ }^{2}$; Zahid Hussain \\ Khan $^{3}$; Mehran Moradi ${ }^{1,}$ \\ ${ }^{1}$ Department of Neurosurgery, Imam Khomeini Hospital, Tehran University of Medical Sciences, Tehran, IR Iran \\ ${ }^{2}$ Department of Neurosurgery, Alzahra Hospital, Isfahan University of Medical Sciences, Isfahan, IR Iran \\ ${ }^{3}$ Department of Anesthesiology, Imam Khomeini Hospital, Tehran University of Medical Sciences, IR Iran \\ ${ }^{*}$ Corresponding author: Mehran Moradi, Department of Neurosurgery, Imam Khomeini Hospital, Tehran University of Medical Sciences, Tehran, IR Iran. Tel: +98-9126850514, E-mail: \\ drmoraim@gmail.com
}

Received: August 16, 2014; Revised: October 10, 2014; Accepted: November 8, 2014

\begin{abstract}
Background: Blood loss during spinal decompression and fusion is high and at times more than the patient's total estimated blood. Increased blood loss may increase the risks of morbidity and eventually length of hospital stay (LOS).

Objectives: The aim of this study was to identify predictor factors of blood transfusion requirements and the length of hospital stay in adult patients who underwent lumbosacral surgery.

Materials and Methods: This was a multicenter cross-sectional study to predict factors of hospital length of stay (LOS) and intraoperative red cell transfusion in patients undergoing major posterior lumbar spinal surgeries. In this study, 298 patients who needed spinal surgery were enrolled.

Results: Multiple linear regression results revealed the following information. Among variables that had significant association with the volume of intraoperative blood loss, considerable predictors were the number of level fused $\left(R^{2}=0.42\right)$, mean intraoperative $\operatorname{SBP}\left(R^{2}=\right.$ $0.22)$, length of operation $\left(R^{2}=0.31\right)$ and increasing age $\left(R^{2}=0.37\right)$. Significant predictors for the length of hospital stay were increasing age $\left(\mathrm{R}^{2}=0.22\right)$, much more comorbid conditions $\left(\mathrm{R}^{2}=0.30\right)$, operation length $\left(\mathrm{R}^{2}=0.27\right)$, the number of level fused $\left(\mathrm{R}^{2}=0.21\right)$ and the volume of intraoperative blood loss $\left(\mathrm{R}^{2}=0.29\right)$. The results of logistic regression revealed that length of operation, preoperative Hb value, number of level fused and mean intraoperative SBP considerably predicted the need for intraoperative blood transfusion.

Conclusions: Diminishing intraoperative SBP could decrease intraoperative blood loss and eventually less red cell transfusion and shorter LOS. Besides, correcting preoperative anemia in female patients before elective surgeries could decrease a need for red cell transfusions and ultimately decreased red cell transfusion complication rate and shorter hospital LOS.
\end{abstract}

Keywords:Surgery; Spine; Blood Transfusion; Blood

\section{Background}

Blood loss during spinal decompression and fusion is high and at times or more than the patient's total estimated blood. Transfusion is associated with significant risks including blood transfusion-related infections such as hepatitis $\mathrm{B}$ and $\mathrm{C}$ and human immunodeficiency virus, hemolytic reaction, transfusion-related lung injury and transfusion associated graft-versus-host disease (1-9). As well, there is a major concern in many developing countries where there is a high prevalence of such infections and transfusion services are inadequately prepared to screen blood thoroughly $(2,3)$. Identifying predictors of blood transfusion in this sort of surgery assists to reduce the amount of blood loss and red cell transfusion. Requirement of transfusion is associated with various factors. Number of levels fused and age had been the most considerable factors predicting intraoperative blood loss (IBL) and blood transfusion (1-4). In addition, patient preoperative hemoglobin concentration, method of surgery, number of spinal levels decompressed, history of pulmonary disease and decreased amount of autologous blood available, are other significant factors affecting IBL, operation length, blood transfusion and LOS (1-8).

\section{Objectives}

This multicenter study was conducted to identify predictive factors of blood transfusion requirements and the length of hospital stay in adult patients who underwent spinal surgery in Imam Khomeini and Baqiyatallah University Hospitals in Tehran and Alzahra University Hospital in Esfahan, Iran, from April 2012 to June 2013.

\section{Materials and Methods}

This was a multicenter cross-sectional study to predict factors of hospital length of stay (LOS) and intraoperative red cell transfusion in patients undergoing major pos- 
terior lumbar spinal surgeries between April 2012 and June 2013. In this study, 298 patients who needed spinal surgery for spinal stenosis, spondylolisthesis and fracture were enrolled. Revision surgeries were not included. Patient data including age, gender, weight, height, Body Mass Index (BMI = weight $\left.[\mathrm{kg}] / \mathrm{Height}\left[\mathrm{m}^{2}\right]\right)$, preoperative and postoperative hemoglobin $(\mathrm{Hb})$ values, preoperative anemia $(\mathrm{Hb}<12 \mathrm{~g} / \mathrm{dL})$, type of surgery, number of level fused and number of screws were recorded. History of diabetes mellitus type 2 (DM2) and hypertension (HTN) who were under medication, as well cardiac diseases were assessed as major comorbidities in this study. History of myocardial infarction, cardiac insufficiency, cardiovascular diseases, cardiac arrhythmia, atrial fibrillation, mitral valve prolapsed and chronic stable angina were considered as cardiac diseases. LOS, intraoperative blood loss, a requirement of blood transfusion and intraoperative SBP were considered as dependent factors. LOS was defined as the date of admission to the discharge date. Number of sponges plus the volume of blood in suction bottles and during admission no particular complication such as cardiopulmonary arrest, renal failure, neuronal damage, deep venous thrombosis, pulmonary embolism and mortality were recorded. Statistical analysis was performed using student t-test for continuous variables. Associations between variables were analyzed by logistic regression analysis. Both univariate and multilinear regression analyses were performed to determine predictive variables for LOS and the volume of PBL. Statistical Package for Social Sciences (SPSS Inc., Chicago, IL) was used for all tests. $\mathrm{P}<0.05$ was considered statistically significant. The study protocol was approved by the Hospitals' Ethics Committee and the Research Ethics Committee of Tehran University of Medical Sciences (TUMS). Each patient signed an individual consent form before the operation.

\section{Results}

Among 298 patients who underwent major lumbar spinal surgeries, the most common type of surgery was operation due to spondylolisthesis $(n=123,41.3 \%)$, followed by spinal decompression with instrumentation $(n=117,39.3 \%)$ and fixation due to fractures $(n=58$, $19.5 \%$ ). According to statistical analysis, mean age and average of operation length were significantly higher in patients who had operation due to spinal stenosis compared to other groups. The average of preoperative and postoperative $\mathrm{Hb}$, intraoperative blood loss and red cell transfusion had no significant difference between the groups (Table 1).

The average of laminectomy level was $3.63 \pm 0.10$ (range 1-10) and the mean number of screws was $6.7 \pm 0.16$ (minimum 4 to maximum 16). Mean postoperative LOS between the groups was $3.62 \pm 0.07$ (range 1-10) days. LOS in patients who had operation due to fractures was much higher compared to other groups. The mean of preopera- tive $\mathrm{Hb}$ in men was $14.08 \pm 0.11$ and $12.59 \pm 0.21$ in women $(\mathrm{P}=0.000)$. There were seventeen men $(10.4 \%)$ and twenty women (14.8\%) with a preoperative $\mathrm{Hb}$ less than $12 \mathrm{mg} / \mathrm{dL}$ $(P=0.02)$. One hundred and seventy nine patients $(60.1 \%)$ had no need for an intraoperative red cell transfusion. Whereas, 119 (39.9\%) required an intraoperative red cell transfusion, classified as spinal decompression with instrumentations (40.2\%), surgeries due to spondylolisthesis (42.3\%) and fixation due to fractures (34.5\%). Length of operation, age $>50$ years, increasing BMI, mean intraoperative SBP, the number of levels fused and the number of screws were considerably associated with the volume of intraoperative blood loss. The following factors were significantly associated with postoperative LOS: intraoperative blood loss, operation length, age $>50$ years, more comorbid conditions and the number of level fused and screws (Table 2). Multiple linear regression results

Table 1. Comparison of Different Variables Between the Three Groups of Major Spine Surgery

\begin{tabular}{lcc}
\hline Variables & Groups, mean \pm SE & P Value \\
\hline Age, $\mathbf{y}$ & & 0.000 \\
\hline Canal stenosis & $58.60 \pm 1.08$ & \\
\hline Lystesis & $47.81 \pm 1.14$ & \\
\hline Fracture & $38.53 \pm 2.74$ & \\
\hline Hb before surgery, mg/dL & & $>0.05$ \\
\hline Canal stenosis & $13.80 \pm 0.12$ & \\
\hline Lystesis & $13.16 \pm 0.25$ & \\
\hline Fracture & $13.14 \pm 0.20$ & \\
\hline Hb after surgery, mg/dL & & $>0.05$ \\
\hline Canal stenosis & $12.07 \pm 0.13$ & \\
\hline Lystesis & $11.49 \pm 0.23$ & \\
\hline Fracture & $11.32 \pm 0.13$ & \\
\hline Operative bleeding, mL & & $>0.05$ \\
\hline Canal stenosis & $773.16 \pm 53.83$ & \\
\hline Lystesis & $901.62 \pm 45.93$ & \\
\hline Fracture & $774.13 \pm 43.89$ & \\
\hline Number of pack cell & & 0.000 \\
\hline Canal stenosis & $188.41 \pm 3.86$ & \\
\hline Lystesis & & \\
\hline Fracture & $0.88 \pm 0.12$ & \\
\hline Duration of admission, d & $0.95 \pm 0.12$ & \\
\hline Canal stenosis & $0.48 \pm 0.09$ & \\
\hline Lystesis & & \\
\hline Fracture & $3.38 \pm 0.08$ & \\
\hline Duration of operation, min & & \\
\hline Canal stenosis & & \\
\hline Lystesis & & \\
\hline Fracture & & \\
\hline & & \\
\hline
\end{tabular}


Miri M et al.

revealed the following information. Among variables with a significant association with the volume of intraoperative blood loss, considerable predictors were the number of level fused $\left(R^{2}=0.42\right)$, mean intraoperative $\operatorname{SBP}\left(R^{2}\right.$ $=0.22)$, length of operation $\left(R^{2}=0.31\right)$ and increasing age $\left(R^{2}=0.37\right)$. Significant predictors for the length of hospital stay were increasing age $\left(R^{2}=0.22\right)$, more comorbid conditions $\left(R^{2}=0.30\right)$, operation length $\left(R^{2}=0.27\right)$, the number of level fused $\left(R^{2}=0.21\right)$ and the volume of intraoperative blood loss $\left(\mathrm{R}^{2}=0.29\right)$. The results of logistic regression revealed that length of operation, preoperative $\mathrm{Hb}$ value, and number of level fused and mean intraoperative SBP considerably predicted the need for intraoperative blood transfusion (Table 3 ).

\begin{tabular}{|c|c|c|c|c|}
\hline Categorical variable & No. (\%) & OT, min & BL, $\mathbf{m L}$ & LOS, d \\
\hline \multicolumn{5}{|l|}{ Gender } \\
\hline Male & $163(54.7)$ & $188.06 \pm 5.47^{c}$ & $825.82 \pm 41.24^{c}$ & $3.71 \pm 0.1^{\mathrm{c}}$ \\
\hline Female & $135(45.3)$ & $198.62 \pm 3.62$ & $827.03 \pm 43.10$ & $3.51 \pm 0.08$ \\
\hline \multicolumn{5}{|l|}{ Smoker } \\
\hline Yes & $53(17.8)$ & $199.88 \pm 15.55^{\mathrm{C}}$ & $941.50 \pm 91.54^{\mathrm{c}}$ & $3.72 \pm 0.08^{C}$ \\
\hline No & $255(82.2)$ & $191.32 \pm 2.47$ & $801.46 \pm 30.22$ & $3.45 \pm 0.14$ \\
\hline \multicolumn{5}{|l|}{ Age } \\
\hline$\leq 50$ Years & $156(52.3)$ & $184.76 \pm 4.78^{d}$ & $732.65 \pm 34.29^{d}$ & $3.44 \pm 0.11^{d}$ \\
\hline$\geq 51$ Years & $142(47.7)$ & $204.28 \pm 5.08$ & $908.97 \pm 47.59$ & $3.75 \pm 0.08$ \\
\hline \multicolumn{5}{|l|}{ Blood loss } \\
\hline$\leq 500 \mathrm{~mL}$ & $107(35.9)$ & $163.77 \pm 5.28^{d}$ & - & $3.27 \pm 0.07^{\mathrm{d}}$ \\
\hline$\geq 501 \mathrm{~mL}$ & $191(64.1)$ & $209.13 \pm 3.99$ & & $3.81 \pm 0.1$ \\
\hline \multicolumn{5}{|l|}{ Operative time } \\
\hline$\leq 180 \mathrm{~min}$ & $165(55.4)$ & $611.87 \pm 27.53^{d}$ & - & $3.34 \pm 0.1^{\mathrm{d}}$ \\
\hline$\geq 181 \mathrm{~min}$ & $133(44.6)$ & $1092.48 \pm 48.33$ & - & $3.96 \pm 0.08$ \\
\hline \multicolumn{5}{|c|}{ Mean Systolic blood pressure } \\
\hline$\leq 110 \mathrm{~mm} \mathrm{Hg}$ & $244(81.9)$ & $188.66 \pm 3.95^{d}$ & $538.88 \pm 47.01 \mathrm{~d}$ & $3.62 \pm 0.08^{c}$ \\
\hline$\geq 110 \mathrm{~mm} \mathrm{Hg}$ & $44(18.1)$ & $211.88 \pm 4.07$ & $569.23 \pm 41.42$ & $3.71 \pm 0.17$ \\
\hline \multicolumn{5}{|l|}{ BMI } \\
\hline $20-25 \mathrm{~kg} / \mathrm{m}^{2}$ & $52(17.4)$ & $198.23 \pm 6.83^{c}$ & $731.29 \pm 37.84^{d}$ & $3.48 \pm 0.11^{\mathrm{c}}$ \\
\hline $26-30 \mathrm{~kg} / \mathrm{m}^{2}$ & $163(54.7)$ & $192.20 \pm 3.10$ & $810.12 \pm 40.34$ & $3.61 \pm 0.11$ \\
\hline $31-35 \mathrm{~kg} / \mathrm{m}^{2}$ & $67(22.5)$ & $198.32 \pm 11.80$ & $862.20 \pm 10.25$ & $3.52 \pm 0.10$ \\
\hline $36-40 \mathrm{~kg} / \mathrm{m}^{2}$ & $16(5.4)$ & $201.84 \pm 3.42$ & $890.12 \pm 34.33$ & $3.71 \pm 0.07$ \\
\hline \multicolumn{5}{|l|}{ Major comorbidities } \\
\hline Hypertension & $52(17.44)$ & $196.15 \pm 11.29^{\mathrm{C}}$ & $738.65 \pm 80.09^{C}$ & $3.92 \pm 0.18^{d}$ \\
\hline Diabetes & $40(13.42)$ & $193.46 \pm 15.56^{\mathrm{C}}$ & $616.66 \pm 45.25^{c}$ & $3.69 \pm 0.06$ \\
\hline Heart disease & $30(10.06)$ & $188.11 \pm 12.01^{\mathrm{C}}$ & $612.12 \pm 30.16^{c}$ & $3.87 \pm 0.11$ \\
\hline Without comorbidities & $203(68.12)$ & $189.28 \pm 3.17^{c}$ & $648.76 \pm 27.71^{c}$ & $3.13 \pm 0.08$ \\
\hline \multicolumn{5}{|l|}{ Laminectomy } \\
\hline$\leq 3$ & $158(53)$ & $161.29 \pm 2.73^{d}$ & $517.78 \pm 2.73^{d}$ & $3.29 \pm 0.07^{d}$ \\
\hline$\geq 4$ & $140(47)$ & $197.38 \pm 6.17$ & $809.28 \pm 42.58$ & $3.99 \pm 0.11$ \\
\hline \multicolumn{5}{|l|}{ Number of screw } \\
\hline$\leq 4$ & $87(29.2)$ & $152.70 \pm 3.70^{\mathrm{d}}$ & $47885 \pm 22.66^{\mathrm{d}}$ & $3.25 \pm 0.09^{d}$ \\
\hline$\geq 5$ & $211(70.8)$ & $188.78 \pm 784.35$ & $727.25 \pm 31.33$ & $3.77 \pm 0.09$ \\
\hline
\end{tabular}

\footnotetext{
a Abbreviations: BL, blood loss; LOS, length of hospital stay; OT, operative time.

$\mathrm{b}$ Data are presented as Mean \pm SE or No. (\%).

${ }^{\mathrm{c}} \mathrm{PV}$ Value $>0.05$.

$\mathrm{d}_{\text {PValue }}<0.05$
} 
Miri M et al.

\begin{tabular}{lccc}
\hline Table 3. Predictive Factors for Intraoperative Blood Transfusion & & \\
\hline Variables & Odds Ratio & 95\%CI & P Value \\
\hline Operative time, min & 1.029 & $1.021-1.037$ & 0.000 \\
Mean systolic blood pressure & 1.021 & $1.019-1.036$ & 0.30 \\
Pre-op Hb,\% & 0.758 & $0.632-0.908$ & 0.003 \\
Level of fusion & 1.398 & $1.333-1.727$ & 0.002 \\
\hline
\end{tabular}

\section{Discussion}

Several previous studies documented that posterior lumbar spine surgeries frequently lead to massive intraoperative blood hemorrhage. However, these kinds of surgery often require intraoperative blood transfusion (1-4). Our study was conducted to identify factors associated with intraoperative blood loss and red cell transfusion during major lumbar spine surgeries. However, modifying these factors could possibly diminish LOS and red cell transfusion complications. According to our results, the number of levels fused (mainly more than three segments) had a significant correlation with intraoperative blood loss. Most clinical studies found that the main predictive factor for intraoperative blood loss was more levels being fused (2, 9-11). These results were in agreement with findings reported by Butler et al. They appraised that the number of levels fused more than three segments was a significant predictor for intraoperative blood loss (1), which was similar to our results. Accordingly, we demonstrated that intraoperative mean SBP was the second momentous variable subsequent to the number of levels fused. It appears that diminishing intraoperative mean SBP could directly to decrease intraoperative blood loss, need for red cell transfusion, short operation time and eventually decreased LOS. Length of operation was important as intraoperative SBP in predicting intraoperative blood loss and eventually LOS.

The operation length in patients who had undergone surgery due to spinal stenosis with fixation was more than those with spondylolisthesis. The duration of surgery due to spondylolisthesis was more than surgeries due to traumatic spinal fractures. As evidenced in our study, although the duration of surgery due to traumatic spinal fractures was less than the two other groups, intraoperative blood loss was similar to other groups. Possible explanation for intraoperative blood loss in these sorts of surgery could be coagulopathy events in trauma phenomena (8). In this study, we observed that number of instruments (especially more than six screws) had a significant correlation with intraoperative blood loss, though in logistic analysis it was not a useful predictor for intraoperative blood loss. The author considered that fixation procedure individually was not the prominent reasons for hemorrhage. One explanation could be procedures including extensive osteotomy and bone decortications for fusion that would increase the risk of hemorrhage and eventually intraoperative blood trans- fusion. As evidenced in our regression analysis, factors including increased age, length of surgery, increased intraoperative mean SBP, more levels of laminectomy and the number of instruments could positively predict intraoperative blood loss. Zheng and colleague found that intraoperative blood loss in males was different from female patients. Hence males inherently have a greater body weight and higher $\mathrm{Hb}$ value could cause more intraoperative blood loss (9). In our study, no difference was observed between the two genders. Previous studies revealed that the duration of hospital LOS was considerably increased in female patients, but it was not observed in our study. One explanation could be that there was no significant difference in the preoperative anemia $(\mathrm{Hb}<$ $12 \mathrm{~g} / \mathrm{dL}$ ), amount of intraoperative blood loss and a need for intraoperative blood transfusion between the two genders. For all the above reasons, correcting preoperative anemia in female patents (if existed) before elective lumbar spinal surgeries could diminish a requirement for blood transfusion and finally decreased LOS. Similar to Zheng et al. survey (9), in our study, more blood loss was observed in obese patients; though, on regression analysis, BMI was not a predictive factor for intraoperative blood loss. Similar reports in Andreshak study (12) found that intraoperative blood loss was increased in obese patients, but it was not statistically meaningful. Actually, contrary techniques in positioning and decreasing intra-abdominal pressure may lead to these differences. Lowering intra-abdominal pressure has an essential role in decreasing bleeding from epidural veins (13-15). In our study, regression analysis revealed that advanced age, operation length, increasing intraoperative systolic blood pressure, more levels fused and number of screws considerably predicted intraoperative blood loss. Study on revision spinal surgeries (9) documented that more levels fused, female gender, unemployment and history of diabetes mellitus would increase hospital LOS. Similar reports in other kinds of surgeries demonstrated that increasing age, female gender, low socioeconomic status and much more comorbidities could increase the duration of hospital stay (16-20). Linear regression analysis results showed that age $>50$ years, volume of intraoperative blood loss (especially more than $500 \mathrm{~mL}$ ), operation length (particularly more than 180 minutes), increased levels of fused (mainly more than three levels) and the number of comorbid conditions could predict increased 
Miri M et al.

hospital LOS. In this study, the average of intraoperative blood transfusion was almost $40 \%$. Zheng et al. found that intraoperative blood transfusion in revision surgeries was $63 \%$ (9). In another clinical study, intraoperative blood transfusion in operations due to scoliosis was $100 \%$, for degenerative disorders was almost $22 \%$ and for spinal stenosis as near $42 \%(10)$. As well, in Butler et al. survey, intraoperative blood transfusion in emergency surgery and elective spinal surgeries was about $26 \%$ (1). Logistic regression analysis showed that operation length, levels fused, intraoperative mean SBP and preoperative $\mathrm{Hb}$ value could be useful predictors for blood transfusion. As similar previous studies documented that levels of fused and preoperative $\mathrm{Hb}$ value were significant predictive factors for intraoperative blood transfusion (1, $11,13,21)$. Despite other studies $(9,19,22,23)$ female gender could not be a useful predictor. As evidenced in our study, one explanation could be that no distinct difference was found between intraoperative blood loss and preoperative anemia $(\mathrm{Hb}<12)$ between the two genders. Advanced age, history of comorbidities and extensive involvement are uncorrectable factors. On the other hand, appropriate preoperative and intraoperative managements including autologous blood transfusion, correction of preoperative anemia, proper positioning during surgery, use of sufficient paralytic agents to reduce intraabdominal pressure, infusion of epinephrine in paraspinal tissues, use of controlled hypotensive anesthesia and anti-fibrinolytic agents $(1,24,25)$ and stopping anticoagulant agents like LMWH, Vitamin K antagonist and NSAIDs (8) could significantly reduce intraoperative blood loss. Our study was a multicenter, prospective, cross-sectional survey and could be used by surgeons and operation room (OR) staff. If we could do all surgeries with a same surgeon and OR staff, our results could be more accurate. Therefore, this study had some limitations such as different hemostatic strategies between different surgeons. Besides, some surgeons prefer to have extended exposure for posterolateral fusions and some others use limited exposure of transverse process for fusions, so these conditions can affect the blood loss. As most studies, the limit for blood transfusion is $\mathrm{Hb}$ value less than $10 \mathrm{~g} / \mathrm{dL}$. Therefore, $\mathrm{Hb}$ below $8 \mathrm{~g} / \mathrm{dL}$ in old adults and below $7 \mathrm{~g} / \mathrm{dL}$ in young adults were considered as limits for red cell transfusion (26). In advanced age, $\mathrm{Hb}$ below $10 \mathrm{~g} / \mathrm{dL}$ has a significant correlation with increased risk of coronary vessels disease. Most surgeons and anesthesiologists have no distinct agreement on it; however, it requires further evaluations. In conclusion, we found that diminishing intraoperative SBP could decrease intraoperative blood loss and eventually less red cell transfusion and shorter LOS. We also found that fixation procedures individually were not the prominent reason for intraoperative blood loss. Osteotomy and bone decortications and increased levels of fusion and instrumentation could increase the volume of blood loss. According to our findings, correction of preoperative anemia in female patients before elective surgeries could decrease a need for red blood cell transfusions and ultimately decreased red blood cell transfusion complications and shorter hospital LOS.

\section{Acknowledgements}

The authors wish to thank all anesthesiology technicians and Ms. Motiee, the nurse of neurosurgery department of Imam Khomeini hospital for their invaluable help in conducting the project.

\section{Authors' Contributions}

Dr. Mojtaba Miri developed the study concept and design and critical revision of the manuscript for important intellectual content; Dr. Gholamreza Farzanegan developed the study concept and design, critical revision of the manuscript for important intellectual content and administrative, technical and material support; Dr. Nasim Khosravi developed the study concept and design, acquisition of data, drafting of the manuscript and administrative, technical and material support; Dr Majid Rezvani administrative, technical and material support and study supervision; Dr. Zahid Hussain Khan technical and material support and study supervision; Dr. Mehran Moradi developed the study concept and design, analysis and interpretation of data, drafting of the manuscript, statistical analysis, administrative, technical and material support.

\section{References}

1. Butler JS, Burke JP, Dolan RT, Fitzpatrick P, O'Byrne JM, McCormack D, et al. Risk analysis of blood transfusion requirements in emergency and elective spinal surgery. Eur Spine J. 2011;20(5):753-8.

2. Johnson RG, Murphy M, Miller M. Fusions and transfusions. An analysis of blood loss and autologous replacement during lumbar fusions. Spine (Phila Pa 1976). 1989;14(4):358-62.

3. Bess RS, Lenke LG. Blood loss minimization and blood salvage techniques for complex spinal surgery. Neurosurg Clin $\mathrm{N} \mathrm{Am}$. 2006;17(3):227-34.

4. Wass CT, Long TR, Faust RJ, Yaszemski MJ, Joyner MJ. Changes in red blood cell transfusion practice during the past two decades: a retrospective analysis, with the Mayo database, of adult patients undergoing major spine surgery. Transfusion. 2007;47(6):1022-7.

5. Eckardt JJ, Gossett TC, Amstutz HC. Autologous transfusion and total hip arthroplasty. Clin Orthop Relat Res. 1978(132):39-45.

6. Giblett ER. Blood group alloantibodies: an assessment of some laboratory practices. Transfusion. 1977;17(4):299-308.

7. Goodnough LT, Marcus RE. Effect of autologous blood donation in patients undergoing elective spine surgery. Spine (Phila $\mathrm{Pa}$ 1976). 1992;17(2):172-5.

8. Brohi K, Cohen MJ, Ganter MT, Matthay MA, Mackersie RC Pittet JF. Acute traumatic coagulopathy: initiated by hypoperfusion: modulated through the protein C pathway? Ann Surg. 2007;245(5):812-8.

9. Zheng F, Cammisa FP, Jr., Sandhu HS, Girardi FP, Khan SN. Factors predicting hospital stay, operative time, blood loss, and transfusion in patients undergoing revision posterior lumbar spine decompression, fusion, and segmental instrumentation. Spine (Phila Pa 1976). 2002;27(8):818-24.

10. Fosco M, Di Fiore M. Factors predicting blood transfusion in different surgical procedures for degenerative spine disease. Eur Rev Med Pharmacol Sci. 2012;16(13):1853-8.

11. Guay J, Haig M, Lortie L, Guertin MC, Poitras B. Predicting 
Miri M et al.

blood loss in surgery for idiopathic scoliosis. Can J Anaesth. 1994;41(9):775-81.

12. Andreshak TG, An HS, Hall J, Stein B. Lumbar spine surgery in the obese patient. J Spinal Disord.1997;10(5):376-9.

13. Bostman O, Hyrkas J, Hirvensalo E, Kallio E. Blood loss, operating time, and positioning of the patient in lumbar disc surgery. Spine (Phila Pa 1976). 1990;15(5):360-3.

14. Lee TC, Yang LC, Chen HJ. Effect of patient position and hypotensive anesthesia on inferior vena caval pressure. Spine (Phila Pa 1976). 1998;23(8):941-7.

15. Relton JE, Hall JE. An operation frame for spinal fusion. A new apparatus designed to reduce haemorrhage during operation.J Bone Joint Surg Br. 1967;49(2):327-32.

16. Ansari MZ, MacIntyre CR, Ackland MJ, Chandraraj E, Hailey D. Predictors of length of stay for transurethral prostatectomy in Victoria. Aust N ZJ Surg. 1998;68(12):837-43.

17. Dropkin MJ. Coping with disfigurement/dysfunction and length of hospital stay after head and neck cancer surgery. ORL Head Neck Nurs. 1997;15(1):22-6.

18. Hayes JH, Cleary R, Gillespie WJ, Pinder IM, Sher JL. Are clinical and patient assessed outcomes affected by reducing length of hospital stay for total hip arthroplasty? J Arthroplasty. 2000;15(4):448-52.

19. Paone G, Higgins RS, Havstad SL, Silverman NA. Does age limit the effectiveness of clinical pathways after coronary artery bypass graft surgery? Circulation. 1998;98(19 Suppl):II41-5.

20. Weintraub WS, Jones EL, Craver J, Guyton R, Cohen C. Determinants of prolonged length of hospital stay after coronary bypass surgery. Circulation. 1989;80(2):276-84.

21. Nuttall GA, Horlocker TT, Santrach PJ, Oliver WC, Jr., Dekutoski MB, Bryant S. Predictors of blood transfusions in spinal instrumentation and fusion surgery. Spine (Phila Pa 1976). 2000;25(5):596-601.

22. Keating EM, Meding JB, Faris PM, Ritter MA. Predictors of transfusion risk in elective knee surgery. Clin Orthop Relat Res. 1998(357):50-9.

23. Nicholls MD, Whyte G. Red cell, plasma and albumin transfusion decision triggers. Anaesth Intensive Care. 1993;21(2):156-62.

24. Lawson JH, Murphy MP. Challenges for providing effective hemostasis in surgery and trauma. Semin Hematol. 2004;41(1 Suppl 1):55-64.

25. Porte RJ, Leebeek FW. Pharmacological strategies to decrease transfusion requirements in patients undergoing surgery. Drugs. 2002;62(15):2193-211.

26. Laupacis A, Fergusson D. Erythropoietin to minimize perioperative blood transfusion: a systematic review of randomized trials The International Study of Peri-operative Transfusion (ISPOT) Investigators. Transfus Med.1998;8(4):309-17. 